FIRM HETEROGENEITY AND FIRM BEHAVIOR WITH CONDITIONAL POLICIES

\author{
Svetlana Demidova \\ Kala Krishna \\ Working Paper 12950 \\ http://www.nber.org/papers/w12950 \\ NATIONAL BUREAU OF ECONOMIC RESEARCH \\ 1050 Massachusetts Avenue \\ Cambridge, MA 02138 \\ March 2007
}

The views expressed herein are those of the author(s) and do not necessarily reflect the views of the National Bureau of Economic Research.

(C) 2007 by Svetlana Demidova and Kala Krishna. All rights reserved. Short sections of text, not to exceed two paragraphs, may be quoted without explicit permission provided that full credit, including (c) notice, is given to the source. 
Firm Heterogeneity and Firm Behavior with Conditional Policies

Svetlana Demidova and Kala Krishna

NBER Working Paper No. 12950

March 2007

JEL No. F1

\section{ABSTRACT}

This paper shows that the result of Ju and Krishna (2002, 2005), i.e., the non-monotonicity in the comparative statics across regimes, disappears, if exporters differ in their productivities, which provides very different predictions about the results of policy changes.

Svetlana Demidova

University of Georgia

Department of Economics

Brooks Hall 528

Athens, GA 30602

demidova@terry.uga.edu

Kala Krishna

Department of Economics

523 Kern Graduate Building

The Pennsylvania State University

University Park, PA 16802

and NBER

kmk4@psu.edu 


\title{
Firm Heterogeneity and Firm Behavior with Conditional Policies
}

\author{
Svetlana Demidova* \\ Kala Krishna ${ }^{\dagger}$ \\ University of Georgia Princeton University, Penn State University and NBER
}

December 2006.

\begin{abstract}
This paper shows that the result of Ju and Krishna $(2002,2005)$, i.e., the non-monotonicity in the comparative statics across regimes, disappears, if exporters differ in their productivities, which provides very different predictions about the results of policy changes.
\end{abstract}

Keywords: Firm heterogeneity, rules of origin.

JEL classification codes: F12, F13.

\section{Introduction}

Trade and domestic policies are often conditional: certain conditions must be met to obtain certain benefits. Content protection schemes in developing countries are one example. They require firms in an industry to use at least some level of domestic inputs. Free Trade Area preferences for members are another example. Producers in the FTA become eligible for zero tariffs on their exports to a partner if the product meets Rules of Origin (ROOs) or special constraints that must be met in order to obtain origin. Otherwise, they pay the going tariff. Our paper argues that firm

${ }^{*}$ Department of Economics, University of Georgia, Athens, GA 30602. E-mail: demidova@terry.uga.edu. Phone: (706) 542 3689. Fax: (706) 5423376.

${ }^{\dagger}$ Department of Economics, Pennsylvania State University, University Park, PA, 16802. Email: kmk4@psu.edu. Tel: (814) 865 1106. Fax: (814) 8634775. 
homogeneity plays a key role in the analyses of such policies. By using a particular policy, the level of ROOs in the FTA, for illustrative purposes, we show that a key result of these analyses vanishes when firm heterogeneity is allowed. This provides a cautionary note in interpreting such results.

Ju and Krishna $(2002,2005)$ show that even when firms are homogeneous, assuming they all make the same choices is not correct. Ex ante identical firms can behave differently in equilibrium if they are indifferent between their alternatives. They show that there are two possible regimes: in the homogeneous regime all firms choose the unique most profitable option. In their example, content protection requires greater use (than dictated by cost minimization considerations alone) of the domestic input, labor. When all firms want to meet this requirement, a stricter restriction shifts the demand for labor, raising its price. In the other regime, the heterogeneous one, some firms choose one option while others choose the other. Indifference between these options must be maintained as the restriction becomes stricter. At given wages, stricter ROOs make profits from meeting the requirement fall below those from not doing so. To keep profits equal, input prices must fall! As a result, the comparative statics for input prices, and through them for other variables, are exact opposites in the two regimes. Previous work, they argued, was thus incomplete, as it only dealt with the homogeneous regime, and misleading, as it had very different comparative statics properties from the heterogeneous one.

In this paper, we show that this is not the entire story either. Introducing differences in firm productivity, which is also more consistent with the empirical evidence ${ }^{1}$, leads to another margin of adjustment, namely, the identity of the marginal firm, eliminating the non-monotonicity in the comparative statics which is the key result in Ju and Krishna $(2002,2005)$. In fact, the comparative statics properties are always like those associated with Ju and Krishna's heterogeneous regime rather than those of the standard homogeneous regime! In the presence of firm heterogeneity,

\footnotetext{
${ }^{1}$ See, for example, Eaton, Kortum and Kramarz $(2004,2005)$.
} 
stricter requirements change the composition of firms. These changes produce the same monotonic adjustments in endogenous variables in both regimes.

We model ROOs similarly to Demidova, Kee and Krishna (2006), allowing ROOs to affect both the fixed and marginal costs of exporting and introduce firm heterogeneity as in Melitz (2003).

\section{The Model}

Consider a small country with $L$ consumers, each of which supplies one unit of labor. Preferences over a continuum of domestically produced goods indexed by $v$ and imported good $z$ are given by

$$
U=\left(z^{\rho}+\int_{v \in \Omega} q(v)^{\rho} d v\right)^{1 / \rho}, 0<\rho<1
$$

where $\Omega$ is the set of available domestic varieties, $q(v)$ is the consumption of variety $v$, and $\sigma=\frac{1}{1-\rho}$ is the elasticity of substitution between varieties. The demand functions are $q(v)=R P^{\sigma-1} p(v)^{-\sigma}$ and $z=R P^{\sigma-1} p_{z}{ }^{-\sigma}$, where $R$ is the aggregate expenditure, and $P$ is the price index, $P^{1-\sigma}=$ $p_{z}^{1-\sigma}+\int_{v \in \Omega} p(v)^{1-\sigma} d v$. We normalize the price of the imported variety $p_{z}$ to 1 .

There is a continuum of monopolistically competitive heterogenous firms of a fixed mass $M .^{2}$ The productivity distribution is Pareto with cumulative function $G(\varphi)=1-\left(\frac{1}{\varphi}\right)^{\beta}, \beta>\sigma$. A firm with productivity level $\varphi$ has $\frac{1}{\varphi}$ per-unit labor requirement.

The firm may also choose to export. The foreign demand ${ }^{3}$ for domestic variety $v$ is $B p_{x}(v)^{-\sigma}$, i.e., we are dealing with a small open economy that has no impact on the rest of the world. Each exporter pays a per-unit tariff $\tau>1$ and a fixed cost $f_{x}$. In addition, it can pay a documentation fixed cost $d$ and invoke the preferences it has been given. However, to access these preferences, it has to meet some $R O O s$, which allow the firm to escape paying $\lambda<1$ share of tariff $\tau$, but involve

\footnotetext{
${ }^{2}$ We assume that $M$ is fixed to follow the assumptions in Ju and Krishna $(2002,2005)$ as closely as possible since their analysis deals with the medium run, where firms can choose what to do but where their mass is given.

${ }^{3}$ Note that we model the foreign demand for domestic variety similarly to Demidova and Rodriguez-Clare (2006).
} 
an additional per-unit $\operatorname{cost} \theta>1$, since now the product has to satisfy origin requirements. The cost functions ${ }^{4}$ of producing $q$ units for domestic and foreign markets are, respectively,

$$
C_{d}(\varphi, q)=\frac{w}{\varphi} q, \quad C_{x}(\varphi, q)=\frac{w \tau}{\varphi} q+w f_{x}, \quad C_{x, R O O}(\varphi, q)=\frac{w \tau(\lambda \theta)}{\varphi} q+w f_{x}+w d
$$

where $w$ is the wage. As a result, the prices set in each case are, respectively, $p_{d}(\varphi)=\frac{w}{\rho \varphi}$, $p_{x}(\varphi)=\frac{w \tau}{\rho \varphi}$, and $p_{x, R O O}(\varphi)=\frac{w \tau(\lambda \theta)}{\rho \varphi}$. For simplicity we assume there are no fixed costs of producing for the domestic market. Thus, all firms in the economy use this option. Moreover, the revenues and profits earned by a firm with productivity level $\varphi$ are, respectively ${ }^{5}, r_{d}(\varphi)=R P^{\sigma-1}\left(\frac{w}{\rho \varphi}\right)^{1-\sigma}$, $r_{x}(\varphi)=B\left(\frac{w \tau}{\rho \varphi}\right)^{1-\sigma}$, and $r_{x, R O O}(\varphi)=B\left(\frac{w \tau(\lambda \theta)}{\rho \varphi}\right)^{1-\sigma}$, and

$$
\pi_{d}(\varphi)=\frac{r_{d}(\varphi)}{\sigma}, \quad \pi_{x}(\varphi)=\frac{r_{x}(\varphi)}{\sigma}-w f_{x}, \quad \text { and } \pi_{x, R O O}(\varphi)=\frac{r_{x, R O O}(\varphi)}{\sigma}-w\left(f_{x}+d\right)
$$

Thus, a firm maximizes $\pi_{d}(\varphi)+\max \left\{0, \pi_{x}(\varphi), \pi_{x, R O O}(\varphi)\right\}$. We can rewrite $\pi_{x, R O O}(\varphi)$ as $\pi_{x}(\varphi)+$ $\pi_{x, r}(\varphi)$, where $\pi_{x, r}(\varphi)=\frac{B}{\sigma}\left(\frac{w \tau}{\rho \varphi}\right)^{1-\sigma}\left((\lambda \theta)^{1-\sigma}-1\right)-w d$ is additional profits from invoking $R O O s .{ }^{6}$ Let us define two productivity cutoffs, $\varphi_{x}^{*}$ and $\varphi_{x, R O O}^{*}$, so that

$$
\begin{aligned}
\pi_{x}\left(\varphi_{x}^{*}\right) & =0 \Leftrightarrow B\left(\frac{w \tau}{\rho \varphi_{x}^{*}}\right)^{1-\sigma}=\sigma w f_{x}, \text { and } \\
\pi_{x, r}\left(\varphi_{x, R O O}^{*}\right) & =0 \Leftrightarrow B\left(\frac{w \tau}{\rho \varphi_{x, R O O}^{*}}\right)^{1-\sigma}\left((\lambda \theta)^{1-\sigma}-1\right)=\sigma w d .
\end{aligned}
$$

Only firms with $\varphi>\varphi_{x}^{*}$ export, and firms with $\varphi>\varphi_{x, R O O}^{*}$ invoke $R O O s$ while exporting. Note

\footnotetext{
${ }^{4}$ The subscript denotes the option used by a firm, i.e., "d" denotes domestic production, "x" denotes exporting without ROOs, and "x,ROO" denotes exporting with ROOs.

${ }^{5}$ An Appendix with detailed proofs and derivations is available upon request.

${ }^{6}$ Similarly, we can define $r_{x, r}(\varphi)=r_{x, R O O}(\varphi)-r_{x}(\varphi)$ as additional revenues from invoking $R O O s$.
} 
that if $\lambda \theta>1$, then no firm will invoke ROOs. We assume that $\lambda \theta<1$. From (1) and (2),

$$
\varphi_{x, R O O}^{*}=A_{R O O} \varphi_{x}^{*}, \text { where } A_{R O O} \equiv\left(\frac{d}{f_{x}} \frac{1}{(\lambda \theta)^{1-\sigma}-1}\right)^{\frac{1}{\sigma-1}}
$$

i.e., if $A_{R O O}>1, \varphi_{x, R O O}^{*}>\varphi_{x}^{*}$. Thus, we need to consider two cases. First, if $R O O s$ are relatively strict and documentation costs are large, then $A_{R O O}>1$ and only the most productive exporters meet ROOs. This is analogous to the heterogenous regime in $\mathrm{Ju}$ and Krishna $(2002,2005)$, where the restriction is strict enough so that firms are not strictly better off meeting it. Second, if $R O O s$ are lax and documentation costs are small, then $A_{R O O} \leq 1$ and all exporting firms meet ROOs. This is analogous to the homogeneous regime in Ju and Krishna $(2002,2005)$.

The Heterogenous Regime. If $A_{R O O}>1$, then $\varphi_{x, R O O}^{*}>\varphi_{x}^{*}$, i.e., only some share of exporters invoke ROOs. As depicted in Figure 1(a), the profits of exporters are linear in $\varphi^{\sigma-1}$. Moreover, the line corresponding to $\pi_{x}(\varphi)$ is flatter than the line corresponding to $\pi_{x, R O O}(\varphi)$, since $\lambda \theta<1$, and has a higher intercept. The intersection of these lines gives the productivity cutoff $\varphi_{x, R O O}^{*}$, so that firms with $\varphi>\varphi_{x, R O O}^{*}$ export with invoking $R O O s$ and getting tariff preferences as additional profits from doing so cover the documentation cost $d$. Firms with $\varphi \in\left[\varphi_{x}^{*}, \varphi_{x, R O O}^{*}\right)$ export without meeting ROOs, while firms with $\varphi<\varphi_{x}^{*}$ do not export at all. Aggregate income in the economy is given by the sum of wages and $\operatorname{rents}^{7}: R=w L+\Pi_{d}+\Pi_{x}+\Pi_{x, r}$, where

$$
\begin{gathered}
\Pi_{d}=\int_{1}^{\infty} \pi_{d}(\varphi) M d G(\varphi)=\frac{1}{\sigma} R P^{\sigma-1} \Psi, \Psi=\eta M\left(\frac{\rho}{w}\right)^{\sigma-1}, P^{1-\sigma}=1+\Psi, \\
\Pi_{x}=\int_{\varphi_{x}^{*}}^{\infty} \pi_{x}(\varphi) M d G(\varphi)=w M_{x} f_{x}[\eta-1], \eta=\frac{\beta}{\beta-(\sigma-1)}, \\
\Pi_{x, r}=\int_{\varphi_{x, R O O}^{*}}^{\infty} \pi_{x, r}(\varphi) M d G(\varphi)=w M_{x, \operatorname{ROO} d[\eta-1],}
\end{gathered}
$$

\footnotetext{
${ }^{7}$ Since $M$ is fixed, rents are not competed away ex ante and so must enter income.
} 
Figure 1: 2 Regimes

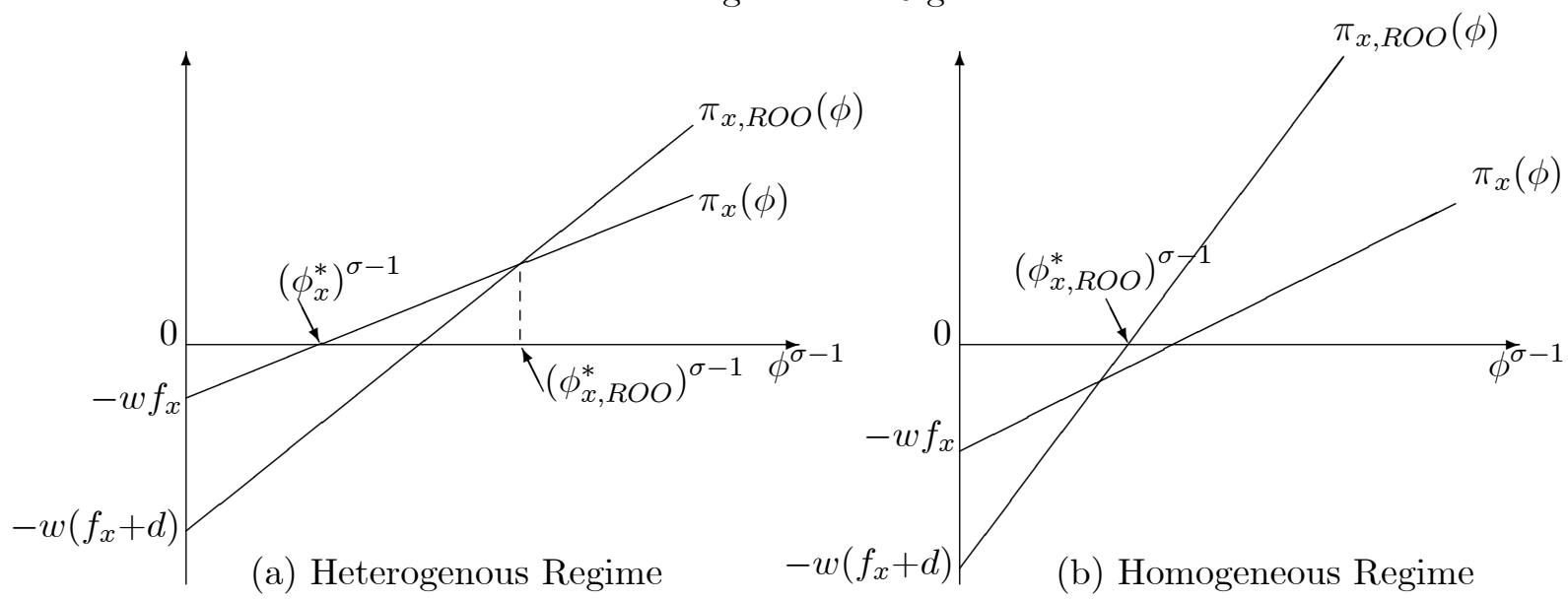

and $M_{x}=\left(1-G\left(\varphi_{x}^{*}\right)\right) M=\left(\varphi_{x}^{*}\right)^{-\beta} M, M_{x, R O O}=\left(1-G\left(\varphi_{x, R O O}^{*}\right)\right) M=\left(\varphi_{x, R O O}^{*}\right)^{-\beta} M$. Thus,

$$
R=\frac{w L+\Pi_{x}+\Pi_{x, r}}{1-\frac{1}{\sigma} P^{\sigma-1} \Psi}=\frac{w L+w f_{x} M_{x}(\eta-1)\left[1+\frac{d}{f_{x}}\left(A_{R O O}\right)^{-\beta}\right]}{1-\frac{1}{\sigma} P^{\sigma-1} \Psi}
$$

There are 2 unknown variables, $\varphi_{x}^{*}$ and $w^{8}$, and 2 equilibrium conditions: the supply side of the economy represented by (1) and the demand side represented by the trade balance condition:

$$
p_{z} z=\int_{\varphi_{x}^{*}}^{\infty} r_{x}(\varphi) M d G(\varphi)+\int_{\varphi_{x, R O O}^{*}}^{\infty} r_{x, r}(\varphi) M d G(\varphi) .
$$

Using (4) and the fact that $P^{\sigma-1}=\frac{1}{1+\Psi}$, the left hand side of (5) can be rewritten as $p_{z} z=R P^{\sigma-1}=\frac{w L+w f_{x} M_{x}(\eta-1)\left[1+\frac{d}{f_{x}}\left(A_{R O O}\right)^{-\beta}\right]}{1+\Psi \rho}$, and the right hand side of $(5)$ can be written as $w f_{x} M_{x}(\sigma \eta)\left[1+\frac{d}{f_{x}}\left(A_{R O O}\right)^{-\beta}\right]$. By equalizing them, we get our final equilibrium condition:

$$
L=f_{x} M\left(\varphi_{x}^{*}\right)^{-\beta}\left[1+\frac{d}{f_{x}}\left(A_{R O O}\right)^{-\beta}\right][\sigma \eta-(\eta-1)+(\sigma-1) \eta \Psi]
$$

where $\sigma \eta-(\eta-1)=\frac{\sigma \beta-(\sigma-1)}{\beta-(\sigma-1)}>0$ since $\sigma>1$. Note that from (1), $w$ is increasing in $\varphi_{x}^{*}$, while

\footnotetext{
${ }^{8} \varphi_{x, R O O}^{*}$ can be found from (3).
} 
Figure 2: Equilibrium in Heterogenous Regime

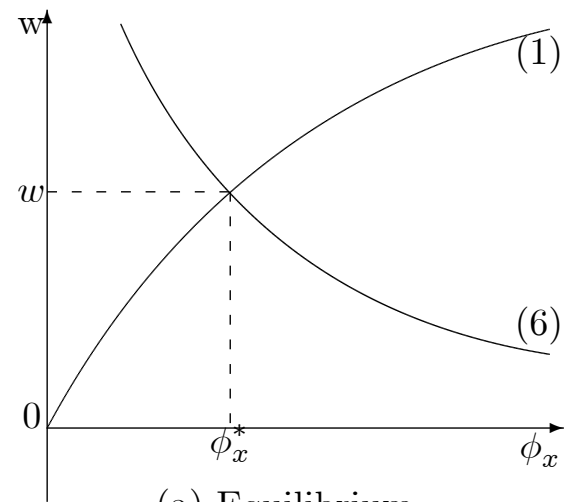

(a) Equilibrium

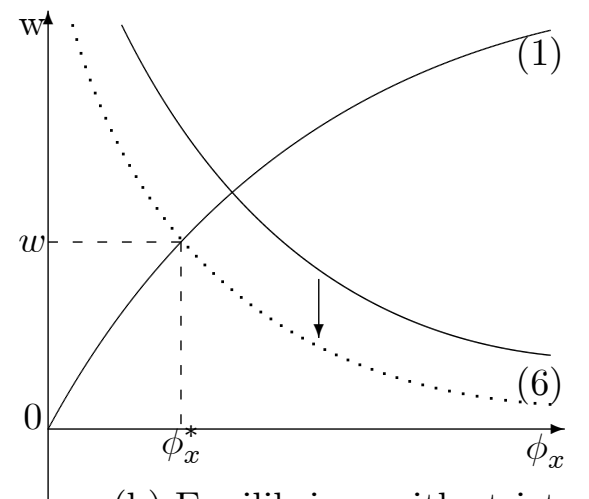

(b) Equilibrium with stricter ROOs

from (6), $w$ is decreasing in $\varphi_{x}^{*}$. We can depict both relationships in Figure 2(a). The intersection of two curves gives $w$ and $\varphi_{x}^{*}$ in the equilibrium.

If $R O O s$ become stricter, i.e., if $d$ or $\theta \lambda$ rises, then $A_{R O O}$ rises and $\left[1+\frac{d}{f_{x}}\left(A_{R O O}\right)^{-\beta}\right]$ falls, shifting the curve corresponding to (6) down as shown in Figure 2(b), and reducing $\varphi_{x}^{*}$ and $w$ in the equilibrium. Substituting for $w$ in terms of $\varphi_{x}^{*}$ in $\Psi$ using (1), and using (3), results in

$L=f_{x} M\left(\varphi_{x, R O O}^{*}\right)^{-\beta}\left[\left(A_{R O O}\right)^{\beta}+\frac{d}{f_{x}}\right]\left[\sigma \eta-(\eta-1)+(\sigma-1) \eta^{2} M \rho^{\rho}\left(\frac{\sigma f_{x}}{B} \tau^{\sigma-1}\right)^{\rho}\left(\frac{A_{R O O}}{\varphi_{x, R O O}^{*}}\right)^{\rho(\sigma-1)}\right]$.

The only variable in $(7)$ is $\varphi_{x, R O O}^{*}$. Stricter $R O O s$ increase $A_{R O O}$, which raises the right hand side of (7), and as a result, $\varphi_{x, R O O}^{*}$ must rise. Thus, stricter $R O O s$ raise $\varphi_{x, R O O}^{*}$

Proposition 1 When not all firms export by invoking preferences, stricter ROOs reduce the wage while reducing the export cutoff and raising the cutoff for those invoking $R O O s$.

The intuition behind these results is the following. First, assume that wage does not change as ROOs become stricter. Then, the profits of exporters, who do not invoke ROOs, remain unchanged. But the productivity cutoff of exporters who meet ROOs rises, while their mass falls. Thus, the aggregate profits from exporting, $\Pi_{x}+\Pi_{x, r}$, as well as consumers' income, fall, reducing the demand 
for each domestic variety and the demand for labor. The equilibrium in the labor market cannot be restored through the exit of firms, thus, wage must fall, making exporting without $R O O s$ more attractive so that the productivity cutoff for exporters $\varphi_{x}^{*}$ falls.

The Homogeneous Regime. The analysis is very similar to that above. When $A_{R O O s} \leq 1$, all exporters invoke ROOs. As depicted in Figure 1(b), the intersection of two lines lies below the horizontal axis. Thus, there is only one productivity cutoff in the equilibrium, $\varphi_{x, R O O}^{*}$, defined as

$$
\pi_{x, R O O}\left(\varphi_{x, R O O}^{*}\right)=0 \Leftrightarrow B\left(\frac{w \tau}{\rho \varphi_{x, R O O}^{*}}\right)^{1-\sigma}(\lambda \theta)^{1-\sigma}=\sigma w\left(f_{x}+d\right)
$$

Aggregate expenditure in the economy $R=w L+\Pi_{d}+\Pi_{x, R O O}$, where $\Pi_{d}=\frac{1}{\sigma} R P^{\sigma-1} \Psi, \Pi_{x, R O O}=$ $\int_{\varphi_{x, R O O}^{*}}^{\infty} \pi_{x, R O O}(\varphi) M d G(\varphi)=w M_{x, R O O}\left(f_{x}+d\right)[\eta-1]$, and $M_{x, R O O}=\left(\varphi_{x, R O O}^{*}\right)^{-\beta} M$. There are 2 unknown variables, $\varphi_{x, R O O}^{*}$ and $w$, and 2 conditions, (8) and the trade balance condition $p_{z} z=\int_{\varphi_{x, R O O}^{*}}^{\infty} r_{x, R O O}(\varphi) M d G(\varphi)$. Using the same technique as before, it can be rewritten as

$$
\begin{aligned}
L & =M\left(f_{x}+d\right)\left(\varphi_{x, R O O}^{*}\right)^{-\beta}[\sigma \eta-(\eta-1)+(\sigma-1) \eta \Psi], \text { or } \\
L & =M \frac{\tau^{-\beta}}{\rho^{-\beta}}\left(\frac{B}{\sigma}\right)^{\frac{\beta}{\sigma-1}}\left(f_{x}+d\right)^{1-\frac{\beta}{\sigma-1}}(\lambda \theta)^{-\beta} w^{-\frac{\beta}{\rho}}\left[\sigma \eta-(\eta-1)+(\sigma-1) \eta^{2} M\left(\frac{w}{\rho}\right)^{1-\sigma}\right]
\end{aligned}
$$

Thus, if ROOs become stricter, i.e., if $d, \lambda$, or $\theta$ rises, then $w$ must fall. Moreover, from (9), $\left(f_{x}+d\right)\left(\varphi_{x, R O O}^{*}\right)^{-\beta}$ must fall, i.e., $\varphi_{x, R O O}^{*}$ must rise. The intuition in this case is the same as before: at a given $w$, stricter ROOs raise the productivity cutoff of exporters all of whom invoke ROOs, reducing their number, aggregate income and the labor demand, so that wage has to fall.

Finally, note that whether or not all exporters meet $R O O s$, stricter $R O O s$ always reduce wages and raise the productivity of those who meet $R O O s$. Thus, even in the "homogeneous case" changes in the extensive margin prevent wages from rising in response to stricter ROOs. 


\section{Conclusion}

What should we take away from this simple exercise? We see our results as not being merely a comment on the generality of an existing paper but as having a broader message. If, as seems empirically indisputable, firms differ in their productivities, making the traditional assumption that firms are identical and behave identically will give the opposite result from allowing for heterogeneity. Why? Because the adjustment on the extensive margin is large and overwhelms the response on the intensive margin. As ROOs become tighter, firms that continue to meet $R O O s$ demand more labor, raising wages. This effect operates via the intensive margin. But firms who stop meeting ROOs demand less labor, pushing wages down. This extensive margin adjustment dominates! Models which only allow for the intensive margin to operate may, thus, give very misleading results.

\section{References}

[1] Demidova, S., H. L. Kee and K. Krishna, 2006, Do Trade Policy Differences Induce Sorting? Theory and Evidence From Bangladeshi Apparel Exporters, mimeo.

[2] Demidova, S. and Andres Rodrigues-Clare, 2006, Export Subsidies, Productivity and Welfare under Firm-Level Heterogeneity, mimeo.

[3] Eaton, J., S. Kortum and F. Kramarz, 2005, An Anatomy of International Trade: Evidence from French Firms, mimeo.

[4] Eaton, J., S. Kortum and F. Kramarz, 2004, Dissecting Trade: Firms, Industries, and Export Destinations, American Economic Review 94(2), 150-154.

[5] Ju, J. and K. Krishna, 2005, Firm Behavior and Market Access in a Free Trade Area with Rules of Origin, Canadian Journal of Economics 38(1), 290-308. 
[6] Ju, J. and K. Krishna, 2002, Regulations, Regime Switches and Non-Monotonicity when NonCompliance is an Option: An Application to Content Protection and Preference, Economic Letters 77, 315-321.

[7] Melitz, M. J., 2003, The Impact of Trade on Intra-Industry Reallocations and Aggregate Industry Productivity, Econometrica 71, 1695-1725. 